\author{
Renata Meira Véras \\ Universidade Federal do Rio Grande do Norte
}

Martha Azucena Traverso-Yépez

Universidade Federal do Rio Grande do Norte

\title{
A maternidade na política de humanização dos cuidados ao bebê prematuro e/ou de baixo peso - Programa Canguru
}

Resumo: O objetivo deste artigo é desenvolver uma reflexão acerca dos modelos de maternidade e família implícitos no documento oficial do Ministério da Saúde sobre o Programa Canguru. Também explora a forma como o Programa é aplicado numa maternidade do Nordeste, apresentado como assistência humanizada para o atendimento ao bebê prematuro e/ou de baixo peso. A perspectiva adotada para este estudo documental é a análise foucaultiana do discurso, que focaliza o papel da linguagem na conformação da vida social e psicológica dos atores sociais envolvidos. A análise mostra que existe um discurso prescritivo, universalista, de caráter impositivo, que posiciona as mulheres como objetos passivos de intervenção, através da idealização da maternidade saudável e da família nuclear típica da classe média.

Palovras-chave: Programa Canguru; prematuridade; maternidade; análise foucaultiana do discurso.

Copyright @ $\odot 2010$ by Revista Estudos Feministas.

PESQUISA NACIONAL POR AMOSTRA DE DOMICÍLIOS, 2006.

\section{Introdução}

O desenvolvimento tecnológico na assistência neonatal, especialmente em relação aos recém-nascidos prematuros, tem contribuído para a diminuição significativa dos índices de mortalidade infantil no Brasil, representando uma queda de $44,9 \% .^{\prime}$ Os partos prematuros ocorrem em situações de risco, tais como gestações na adolescência e em mães com idade acima de 35 anos. Entretanto, outras condições também são evidenciadas: baixo nível educacional materno, tabagismo, hipertensão arterial, diabetes gestacional, infecção do trato geniturinário, ausência de 
${ }^{2}$ Mario Francisco Giani MONTEIRO e Ruben CERVINI, 1992.

${ }^{3}$ José VILLAR et al., 2006.

${ }^{4}$ Raúl Urgino ARÉSTEGUI, 2002. acompanhamento pré-natal, presença de outros filhos com baixo peso ao nascer ${ }^{2}$ e parto cesariano. ${ }^{3}$

Contudo, esses avanços nos cuidados biomédicos às crianças prematuras e/ou de baixo peso, além de aumentarem as chances de sobrevida dos bebês, aumentam a probabilidade de sequelas decorrentes à imaturidade. Essas sequelas demandam atendimento especializado e investmento de tempo e esforços que os pais, especialmente das classes sociais menos favorecidas, têm dificuldade em atender.

Os bebês prematuros são susceptíveis à mortalidade bem como às complicações decorrentes das infecções e das lesões, as quais podem levar à paralisia cerebral, ao retardo mental e a outros distúrbios físicos e neurológicos. ${ }^{4}$ Precisam, portanto, ao nascer, de cuidados especiais intensivos, sendo, muitas vezes, internos em unidades de terapia intensiva neonatais (UTIN), até saírem da situação de risco, que pode demorar entre dias e meses.

Nessa perspectiva, o impacto da condição da prematuridade e/ou do baixo peso no curso do desenvolvimento e na adaptação psicossocial da criança impulsionou o interesse do governo brasileiro em editar portarias e normas, através do Ministério da Saúde, amparadas em um discurso humanizador nessa área. Assim, em 5 de julho do ano de 2000, o Ministério da Saúde publicou a Portaria 693/GM, estabelecendo as Normas de Orientação para a Implantação do Método Canguru. Porém, essa portaria foi revogada, entrando em vigor a Portaria 1.683, de 12 de julho de 2007, observando-se pequenas mudanças em relação à elaboração textual, à ordem de alguns itens e à exclusão de outros. Uma das modificações foi a recomendação da posição canguru na terceira etapa, ou seja, em nível domiciliar. De acordo com a portaria anterior, essa prática deveria ser determinada exclusivamente em função do bemestar da criança, entretanto, na nova portaria passa a estar em função do bem-estar da díade.

O Programa Canguru apresenta-se como um tipo de assistência humanizada para o atendimento do recémnascido prematuro e/ou de baixo peso. Adota a prática de colocar o bebê em contato pele a pele com sua mãe no intuito de fortalecer o vínculo mãe-bebê, incentivar o aleitamento materno e promover maior segurança nos cuidados com seu filho. Dessa forma, cogita-se o interesse por parte do Estado em garantir condições de vida adequadas para essas crianças, assim como minimizar os índices de abandonos e maus-tratos futuros, acrescentando-se também o ganho secundário de reduzir custos com a saúde desses recém-nascidos.

Esse programa foi criado no Hospital San Juan de Dios - Instituto Materno Infantil (IMI) - de Bogotá, Colômbia, em 1979, pelos doutores Edgar Sanabria Rey e Héctor 
5 Marcus Renato CARVALHO e Martha PROCHNIK, 2001.

${ }^{6}$ Zeni Carvalho LAMY et al., 2005.

${ }^{7}$ Natalie CHARPAK, 2001.
Martínez Gomes, em resposta ao elevado índice de mortalidade entre os recém-nascidos prematuros, cuja principal causa era a infecção hospitalar. ${ }^{5}$ A preocupação, na época, era encontrar uma alternativa para a dificuldade de acesso à tecnologia, o que obrigava a equipe de saúde a colocar dois ou três bebês juntos em uma mesma incubadora, multiplicando as possibilidades de infecção. Assim, utilizando as mães como substitutas de tal tecnologia, esse método supriria a sua falta e consequentemente reduziria tanto a mortalidade neonatal intra-hospitalar como também o tempo de permanência das mães e seus bebês prematuros na maternidade.

Atualmente, esse programa vem se desenvolvendo em muitos lugares do mundo, variando sua aplicação no que diz respeito à abrangência, ao tempo de início e término e ao tempo de permanência do bebê na posição canguru. ${ }^{\circ}$ Não há, portanto, um Programa Canguru único, consensual. As formas de aplicação desse método são diversas, variando de acordo com a cultura, as condições sociais e os desenvolvimentos dos serviços de saúde nos quais ele é aplicado.?

No Brasil, desde a implantação oficial do Programa Canguru através da Área de Saúde da Criança da Secretaria de Políticas de Saúde - Ministério da Saúde - no ano 2000 , esse método passou a ser implantado nas maternidades e nas unidades de tratamento intensivo neonatais do SUS em todo o país como uma política de saúde pública. Algumas maternidades, como o Instituto Materno-Infantil de Pernambuco, em Recife, e o Hospital Guilherme Álvaro, em Santos, São Paulo, já vinham aplicando essa técnica como um projeto-piloto. ${ }^{8}$ Entretanto, apenas em 2002 o Ministério da Saúde, em parceria com o Banco Nacional de Desenvolvimento Econômico e Social (BNDES), ${ }^{9}$ e a Fundação Orsa ${ }^{10}$ lançaram um manual de treinamento das equipes de saúde para atuarem no Programa Canguru. ${ }^{11}$

Contudo, os serviços de saúde que aplicam o Programa na atualidade se encontram em estágios bastante heterogêneos de implantação. O padrão comum é o uso do discurso humanizador, estimulando-se a participação da mãe nos cuidados com seu filho, argumentando a necessidade de incentivar a formação do apego mãe-bebê e tornando a mãe a principal responsável pelo seu desenvolvimento.

Tende-se a desconsiderar que esse tipo de intervenção, na avaliação dos doutores Martinez e Sanabria, idealizadores do Programa Canguru, deve ser algo proposto pela equipe de saúde, e nunca uma imposição. Igualmente, que algumas mulheres estão disponíveis, física e emocionalmente, apenas para o contato corpo a corpo (mãe e bebê permanecem vestidos), e não para o contato pele a pele, 
${ }^{12}$ CARVALHO e PROCHNIK, 2001.

que é a base para a transmissão do calor e do estímulo sensorial. ${ }^{12}$

Mesmo reconhecendo a importância do Programa, algumas pesquisas no Brasil têm suscitado reflexões sobre a idealização da maternidade, assim como acerca de aspectos que dificultam a participação das mães, como, por exemplo, a falta de planejamento da gravidez, as perdas

13 Solange Maria Sobottka Rolim MOURA e Maria de Fátima ARAÚJO, 2005; e Tereza Setsuko TOMA, 2003

14 Tereza TOMA, Sónia Isoyama VENÂNCIO e Daniela de Almeida ANDRETTO, 2007.

15 Jefferson de Souza BERNARDES e Vera Sônia Mincoff MENEGON, 2007. em gestações prévias, a falta de apoio da família. ${ }^{13}$ Assim, em um estudo realizado numa maternidade de São Paulo, onde $60 \%$ das usuárias optaram por não participar do Programa Canguru, as principais barreiras relatadas por essas mães foram a existência de outros filhos, a falta de ajuda relativa para as tarefas domésticas e a escassez de recursos para o transporte. ${ }^{14}$

Considera-se, assim, importante estudar as formas como a maternidade e a família são definidas no documento oficial que orienta o Programa Canguru no Brasil, como também analisar de que maneira tais conceitos configuram o papel materno no cotidiano de uma maternidade-escola do Nordeste brasileiro. Nesse teor, os documentos públicos podem ser considerados como práticas discursivas, importantes na manutenção de estratégias de governamentalidade. ${ }^{15}$ São, ao mesmo tempo, produtos e autores sociais, já que a linguagem não apenas torna descritiveis os atos do governo, mas possibilita a sua existência. A linguagem torna-se um instrumento fundamental nesse tipo de análise, na medida em que, por meio dela, objetos discursivos são construídos e posicionamentos são definidos na dinâmica interacional da qual as pessoas fazem parte.

Esta análise faz parte de uma pesquisa mais ampla de doutorado fundamentada na etnografia institucional, a qual almeja estudar o Programa Canguru e as formas de atendimento às mães e aos bebês na citada maternidade, atentando para as práticas institucionais e para a produção de sentidos dos atores sociais sobre a maternidade e os cuidados dessas crianças nesse programa.

\section{Método}

Objetiva-se, então, analisar as construções discur-sivas, especificamente, presentes no Módulo 2 do documen-to oficial de treinamento das equipes do Programa Canguru -Atenção humanizada ao recém-nascido prematuro e/ou de baixo peso - Método Mãe-Canguru: manual do curso - e as possíveis maneiras que podem influenciar na forma de pensar e agir dos atores sociais envolvidos nesse programa. Na perspectiva da análise foucaultiana do discurso, os textos não são considerados apenas como um modo de expres-são, mas também como práticas institucionais, ou seja, como formas de 
${ }^{16}$ Carla WILLIG, 2001.

17 Dorothy SMITH, 2005.

${ }^{18}$ Marjorie DEVAULT e Liza McCOY, 2002. organização, reguladoras e administradoras da vida social. Dessa forma, enquanto esses discursos legitimam e reforçam as relações existentes nas estruturas institucionais, estas, ao mesmo tempo, também apoiam e validam os discursos. ${ }^{16}$

Apresenta-se, assim, a análise discursiva do manual que normatiza o funcionamento do Programa, confrontandoa com a forma como este é aplicado no cotidiano institucional do Programa. Portanto, complementa-se este estudo com dados da observação participante, de entrevistas e de grupos focais desenvolvidos ao longo do primeiro ano de trabalho de campo na maternidade em estudo. Essas estratégias em conjunto facilitam ao investigador analisar os sentidos, os posicionamentos e as relações normatizadoras assumidos pelos participantes. ${ }^{17}$

A maternidade-escola faz parte da Universidade Federal de uma das capitais do Nordeste, sendo referência no atendimento materno-infantil para o estado. Grande parte das mães atendidas é de baixo nível de escolaridade e baixa renda econômica. Elas são usuárias do Sistema Único de Saúde, advinda a maioria delas das cidades circunvizinhas que não possuem serviço de UTI neonatal. Por isso, as mães passam a residir no alojamento conjunto do Programa da maternidade até a alta do bebê, que muitas vezes pode chegar a três meses.

Após a aprovação do Comitê de Ética, através da observação participante e de entrevistas semiestruturadas, buscou-se interagir com os profissionais e com as usuárias do Programa na tentativa de participar da vida deles nesse cenário de convivência. Manter um diário de campo durante as observações se mostrou de suma importância. Muitas vezes as entrevistas formais limitam o fornecimento de informações que podem aparecer mais facilmente nas conversas informais e situações presenciadas. Estas situações informais tendem a evidenciar com maior transparência as relações de poder que modelam as experiências particulares e perpassam o contexto intersubjetivo em questão. ${ }^{18}$

Foram entrevistadas individualmente 11 mães, cujas idades variaram entre 16 e 32 anos e a escolaridade, entre analfabetismo e nível superior. O número de filhos variou entre 1 e 11. Apenas duas mães planejaram a gravidez, como também somente duas mães afirmaram não ter feito o acompanhamento pré-natal.

Três mães eram solteiras, duas estavam casadas e seis afirmaram ter relacionamento estável. Das sete mães que tinham mais de um filho, apenas uma mãe afirmou que todos os filhos eram do mesmo pai. Quatro mães afirmaram que, pelo menos, um dos seus filhos é criado pelas avós, e apenas duas mães residem com o cônjuge e os filhos, as demais dividem a moradia com os pais, irmãos e/ou sogros. 
Além dessas entrevistas, foram realizados seis grupos focais, com uma média de seis mães em cada grupo, proporcionando, assim, um ambiente mais natural que a entrevista individual, uma vez que facilita a exposição de ideias, confrontos e argumentações.

Os funcionários também participaram de três grupos focais, com uma média de quatro em cada grupo. As entrevistas individuais foram desenvolvidas com sete desses funcionários: uma médica, uma enfermeira, duas técnicas em enfermagem, uma terapeuta ocupacional, uma assistente social e um psicólogo. Apenas dois funcionários alegaram ter participado de algum programa de capacitação para atuarem no Programa Canguru.

\section{Análise do documento Atenção huma- nizada ao recém-nascido prematuro elou de balxo peso: manual do curso}

Este manual, considerado instrumento para treinar e normatizar o trabalho das equipes destinadas a atuar no Programa Canguru, apresenta o Programa, discute os aspectos psicoafetivos e biológicos da mãe/pai e do recémnascido prematuro, como também discorre sobre o desenvolvimento e a avaliação comportamental dos bebês, de forma a capacitar os funcionários a trabalharem nesse tipo de intervenção.

O manual foi elaborado por 13 autores, possui 196 páginas e apresenta-se dividido em seis módulos. O primeiro refere-se às políticas de saúde voltadas para o recémnascido prematuro. O segundo, foco de análise deste trabalho, envolve os discursos acerca da construção da maternidade/paternidade, da formação dos laços afetivos entre a família e o filho prematuro e dos aspectos relevantes sobre o desenvolvimento do bebê. O terceiro módulo discorre sobre os aspectos biológicos característicos da prematuridade. Os cuidados com o recém-nascido de baixo peso são tratados no quarto módulo, e o seguimento ambulatorial para os bebês que recebem alta do Programa são discutidos no módulo quinto. Por fim, o sexto módulo traz uma ficha de avaliação institucional sobre o Programa Canguru a ser aplicada nas maternidades.

A análise documental apresenta-se a partir de seis

19 WILLIG, 2001.

20 Martha Azucena TRAVERSOYÉPEZ, 2007. etapas, de acordo com a perspectiva de análise foucaultiana sintetizada por Willig ${ }^{19}$ e utilizada por Traverso-Yépez. ${ }^{20}$ O foco em cada etapa detalha-se a seguir: 1) nas construções discursivas que lidam com a temática da maternidade/ paternidade em situações especiais como a prematuridade e/ou o baixo peso; 2) nos tipos de discursos que agrupam essas construções em categorias mais abrangentes, 
21 John BOWLBY, 1995; René Árpád SPITZ, 1987; e Donald WINNICOTT, 2001.

22 BRASIL, 2002, p. 27.

${ }^{23}$ BRASIL, 2002, p. 28.

${ }^{24}$ Tânia SALEM, 1987. atentando para os juízos de valor envolvidos no texto; 3) na orientação para a ação que esses discursos apontam, considerando o seu caráter funcional; 4) no estudo dos posicionamentos que os discursos viabilizam aos atores sociais envolvidos; 5) no estudo das práticas ou formas em que as construções discursivas e os posicionamentos dos sujeitos nelas contidos abrem ou fecham oportunidades para a ação; e 6) nas formas de subjetivação possíveis a partir da orientação para a ação, dos posicionamentos e das práticas presentes nos textos.

\section{Etapa 1: as construções discursivas}

Este primeiro estágio de análise envolve a identificação das diferentes construções ou objetos discursivos que lidam com a temática da maternidade/paternidade e da família em relação ao bebê prematuro no manual, atentando para a forma como estão construídos e para os argumentos apresentados.-Assim, o tema objeto de estudo é contemplado através dos seguintes objetos discursivos:

1) A construção da parentalidade: o nascimento de um bebê aparece no documento como um momento importante no ciclo vital dos pais, causando repercussões no meio familiar. A maternidade e o papel da mãe no Programa Canguru são discutidos a partir de uma perspectiva idealizada da família nuclear, sustentando-se na perspectiva de autores psicanalistas. ${ }^{21} \mathrm{O}$ manual demonstra um gráfico com a representação de uma família e o texto aponta que a união entre "homem-pai" e "mulher-mãe" recebe influência da família de origem de cada cônjuge, o que irá configurar a sua própria. Esse arranjo, juntamente com o nascimento de um bebê, traz "à tona memórias e lembranças relativas ao nascimento e à infância dos pais, a forma que foram cuidados e atendidos em suas necessidades durante seus primeiros anos de vida". ${ }^{22}$

Assim, o processo da construção da maternidade/ paternidade é desenvolvido através de conceitos, tais como casal grávido, parentalidade, bebê fantasmático, bebê imaginário e bebê real.

Um bebê começa a existir para seus pais muito antes de sua concepção. Ele tem início no desejo que cada homem e cada mulher possuem desde sua tenra infância de um dia formarem uma família e continua sendo formado enquanto o casal vai descobrindo, quando adultos, os dois juntos, como pretendem configurar sua família. ${ }^{23}$

Entretanto, para Salem, ${ }^{24}$ que também analisa o conceito de casal grávido, o laço conjugal não sofre influência direta do campo das relações familiares. A conjuga- 
${ }^{25}$ Göran THERBORN, 2006.

${ }^{26}$ Tânia Maria Gomes SILVA, 2002.

27 PESQUISA NACIONAL POR AMOSTRA DE DOMICÍLIOS, 2006.

${ }^{28}$ BRASIL, 2002, p. 35.

29 PESQUISA NACIONAL POR AMOSTRA DE DOMICÍLIOS, 2006. lidade é suficientemente forte e autorreferida, remetendo para a pressuposição de que a família deve estar dotada de uma identidade interna mais forte do que aquela que vincula cada um de seus membros aos respectivos núcleos de origem.

Da mesma forma, nas construções discursivas apresentadas no manual, percebe-se uma ausência de reflexão sobre o caráter sócio-histórico-cultural das relações parentais e as mudanças sociais na instituição familiar ao longo dos tempos. ${ }^{25}$ De fato, observa-se que a concepção do Programa Canguru centra-se em modelos de família e maternidade idealizados, que podem ser bastante distintos daqueles presentes na população, principalmente na classe de baixa renda, usuária desses serviços. Assim, no Brasil, menos de uma em quatro famílias enquadra-se no modelo da família nuclear, ou seja, pais casados com filhos. ${ }^{26}$ No Nordeste brasileiro, verificou-se um crescimento das famílias com mulheres com filhos e sem cônjuge na chefia familiar, passando de $17,4 \%$ em 1995 para $20,1 \%$ em 2005. ${ }^{27}$

2) A responsabilidade dos pais pelo seu bebê: o documento responsabiliza os pais pelo desenvolvimento de seu bebê, enfatizando reiteradamente a ideia de família nuclear como o meio saudável para receber seu filho: "As relações iniciais entre o bebê e seus pais são consideradas o protótipo de todas as relações sociais futuras". ${ }^{28}$

Observa-se que o desenvolvimento do bebê é analisado apenas a partir da suposta relação saudável entre os pais e entre os pais e os filhos. Aspectos como o contexto social, cultural e econômico, que têm uma enorme contribuição para o comportamento humano, são negligenciados. Ademais, a falta de programas sociais, muitas vezes, faz com que a responsabilidade do governo nos cuidados com a infância seja repassada para a família, que nem sempre tem condições de assumi-la. Por exemplo, em 2005, a proporção de crianças de zero a três anos que frequentava creches era de apenas $13,3 \% .^{29}$

Em alguns casos, por não dispor de um apoio desse tipo ou de familiares, algumas mães ainda solicitavam ajuda dos vizinhos, como apresentado no discurso da terapeuta ocupacional:

Teve uma aqui que deixou dois filhos com a vizinha porque não tinha parente, e já tava quase um mês aqui. A vizinha ligou e disse que ia botar os meninos na rua porque não tinha o que dar de comer a eles, ela pensou que a mulher ia passar um ou dois dias aqui.

Dessa forma, responsabilizar os pais de todo o desenvolvimento do filho é benéfico apenas para normalizar e prescrever formas ideais de maternar/paternar o bebê, como 
30 BRASIL, 2002, p. 28.

31 PESQUISA NACIONAL POR AMOSTRA DE DOMICÍLIOS, 2006.

32 BRASIL, 2002, p. 33. também para se isentar da responsabilidade em oferecer serviços sociais de qualidade.

3) Maternar/paternar se aprende desde criança: para o documento, a maneira de cuidar dos bebês já existe nos pais a partir de conhecimentos preestabelecidos desde sua infância, através dos cuidados recebidos na própria família.

O bebê que surge desse desejo interno do casal está presente em suas fantasias e em suas idealizações há muito tempo, talvez desde o início de suas próprias vidas. Seus primeiros registros podem ser encontrados nas brincadeiras de meninos e meninas que repetem atividades de maternagem e paternagem que observam em seus pais: brincam de bonecas, montam casinhas, criando situações que imitam as atividades que seus pais e mães realizam rotineiramente e que envolvem o cuidado e a atenção com todo o grupo familiar. ${ }^{30}$

Em outras palavras, destaca-se o papel dos processos de socialização, ao mesmo tempo que se reconhece a existência de diferenças culturais no processo de maternar/paternar. A ideia central nesse objeto discursivo é que existem 'raízes universais' quanto à formação de padrões interativos entre o bebê e sua família, partindo da premissa de que os pais já possuem conhecimentos adquiridos no seu próprio âmbito familiar. Assim, eles são apresentados desenvolvendo certas atividades rotineiras estereotipadas, em que a mãe cuida da casa e dos filhos, enquanto o pai se ausenta para trabalhar.

Mais uma vez, a concepção da família nuclear e idealizada é aceita a partir da premissa de que todos os indivíduos tiveram uma família acolhedora e foram cuidados de maneira saudável. Dessa forma, espera-se que os pais cuidem do seu bebê da mesma maneira com que foram maternados, ou seja, de modo satisfatório. Entretanto, deve-se levar em consideração a situação socioeconômica desses pais. O rendimento familiar per capita é uma variável impor-tante para o bem-estar das crianças. No Nordeste, verificou-se que $44 \%$ das crianças até os seis anos de idade em 2005 viviam com famílias cujo rendimento não ultrapassava meio salário mínimo mensal, colocando-as abaixo da linha da pobreza. ${ }^{31}$

4) A responsabilidade de um pai idealizado: a figura do homem surge no manual como um pai sempre presente que apoia a esposa nesse momento de acompanhar o bebê prematuro. "É fundamental que cada vez mais possamos observar no pai, companheiro da mãe no (ato de) criar e cuidar dos filhos, as implicações que a necessidade de assumir novas funções e papéis determina em seu funcionamento psíquico". ${ }^{32}$ 
${ }^{33}$ BRASIL, 2002, p. 34.

${ }^{34}$ BRASIL, 2002, p. 29-30.

35 Phillip ARIÈS, 1981; Elisabeth BADINTER, 1985; e Jacques DONZELOT, 1986.

${ }^{36}$ BADINTER, 1985.
O pai figura como o provedor das necessidades da família, esforçando-se para oferecer à sua prole e à sua esposa tudo que for necessário para o bem-estar da instituição familiar: "A chegada desse novo membro da família (o bebê) lhe faz um sem-número de exigências: preocupase com sua capacidade de prover as necessidades da família, oferecer apoio à esposa, dispor de tempo para cuidar do bebê". ${ }^{33}$

Entretanto, como já destacado anteriormente, três das participantes não tinham marido e apenas duas mães casadas residiam com o cônjuge e os filhos, mas as demais dividiam a moradia com os pais, irmãos e/ou sogros. Observase, ainda, o descaso de alguns pais em uma entrevista com uma das médicas do Programa Canguru:

Olhe, eu já peguei pais aqui de todo tipo, pai dedicado, pai que fazia canguru, pai que chega aqui na hora da visita e descontenta a mãe, ele chega aqui e diz você já está aqui há dois meses, se não voltar pra casa eu vou arrumar outra, ele tortura a mãe. E a gente proibiu a entrada desse pai, ele estava interferindo no desenvolvimento do bebê.

5) O processo do desenvolvimento do vínculo afetivo mãe-bebê: o amor materno é apresentado no manual a partir de uma perspectiva inata e comum a todas as mulheres. A formação do vínculo afetivo é associada aos sentimentos surgidos durante a gravidez relacionados com o desenvolvimento físico do feto e com as mudanças no corpo e no psiquismo materno. Apresenta-se um modelo das fases que a mulher experimenta para desempenhar a maternidade: "1) aceitando a novidade, 2) os primeiros movimentos, 3) aprendendo sobre o futuro do bebê e 4) constelação da maternidade". ${ }^{34}$

Essa perspectiva ideológica que restringe o papel da mulher à maternidade está sendo questionada e redefinida pela nova configuração de família e mulher da atualidade. Os historiadores demonstram que o lugar e a valorização da maternidade no âmbito sociocultural variaram ao longo de diferentes momentos históricos e contextos culturais em resposta a interesses sociais mais amplos, como os de ordem econômica, demográfica e política. ${ }^{35}$

A médica da maternidade onde foi realizada a pesquisa de campo, ao falar sobre o amor materno, posicionase em oposição à teoria do instinto maternal. Na sua concepção, o amor surge a partir do convívio ou, como já atentava Elisabeth Badinter, ${ }^{36}$ como consequência de um interesse próprio da mãe:

Uma mãe aqui tomou citotec (remédio abortivo) e ela nem queria ver o bebê, mas a gente 'colocou eles' no 
${ }^{37}$ BRASIL, 2002, p. 46. alojamento. Ela não queria o bebê, ameaçava jogar ele pela janela, mas aos poucos ela começou a criar o vínculo. Antes ela deixava o bebê na cama e ia fumar, não cuidava nada dele, mas aos poucos ela foi mudando porque ela viu que todo mundo ia embora e ela ficava.

Entretanto, a manutenção da perspectiva do instinto maternal pode ser relevante para o Estado, uma vez que dessa forma ameniza a falta de imprescindíveis serviços assistenciais voltados para a infância em geral. No caso específico das crianças prematuras, devido à grande probabilidade de apresentar sequelas, a presença dos serviços públicos é ainda mais necessária. Sem esse apoio socioinstitucional para esses bebês que demandam cuidados especiais, deixa-se à mãe, identificada como cuidadora principal, toda a responsabilidade nos cuidados com a criança.

6) Peculiaridade dos cuidados com o bebê prematuro: as normas oferecem subsídios para capacitar os profissionais da saúde, a fim de favorecer a formação do vínculo afetivo entre a família e o bebê. Essa ação é considerada 'profilática', de forma a evitar danos psicológicos nas relações sociais futuras: "A característica maior desse trabalho com a família na UTI Neonatal refere-se a uma ação profilática quanto ao desenvolvimento das relações desse grupo familiar, além de minimizar o sofrimento daqueles que têm um bebê internado". ${ }^{37}$

Porém, observa-se que as normas são apenas prescritas, esquecendo-se de que cada instituição de saúde possui um funcionamento próprio, nem sempre adequado para esse tipo de assistência. A partir do entendimento e da forma de atuação de cada gestor de hospital sobre o Programa, assim como a disponibilidade dos recursos econômicos e as particularidades da população a ser atendida, é que se configura o caráter do Programa Canguru em cada maternidade.

Na maternidade pesquisada é evidente que a maioria das mães não sabe que tem o poder de decidir ir para casa, conforme a fala da enfermeira: "Elas [mães] chegam acreditando que têm que ficar enquanto o bebê estiver aqui". Ou praticam a posição canguru por convencimento da médica: "Eu vejo uma data próxima, São João, por exemplo, e digo: olhe, vocês vão passar o São João aqui, começo a torturar, no bom sentido, pra que elas colaborem". Ou ainda, através de uma apelação ao amor materno a fim de sensibilizar as mães e convencê-las de permanecerem internadas, conforme discurso da assistente social:

Mas eu trabalho muito a questão do vínculo com essas mães. Falo do cheiro, que o bebê reconhece o cheiro dela. Que ele sente quando ela chega. Aí eu digo: 
${ }^{38}$ BRASIL, 2002, p. 38.

passe a mão nele e veja como ele fica diferente. Quando as enfermeiras tocam é um jeito, quando você toca é diferente. Eu tô errada, eu sei, mas eu trabalho assim [...] Porque eu apelo pra elas ficarem, mas é pra o bem do bebê.

\section{Etapa 2: os tipos de discursos}

Nesse nível de análise, atenta-se para os juízos de valor que perpassam os discursos e situam as construções discursivas através de um determinado viés. Assim, observase que um discurso psicologista constitui-se como principal alicerce para as práticas discursivas no documento oficial.

1) Psicologização do amor materno e da família idealizada: ao analisar as justificativas para a implementação do Programa apresentadas nas normas que o regem, encontra-se um referencial teórico baseado na perspectiva de autores psicanalistas que ressalta a importância da criação do vínculo afetivo entre a mãe e o bebê. Assim, no texto afirma-se que "não devemos fazer um julgamento precipitado quando achamos que um bebê não será amado simplesmente porque não foi devidamente planejado e desejado, porque o desejo de ter filhos pode ser consciente e também inconsciente". ${ }^{38}$

Nota-se, nesses discursos, o processo de psicologização, ao afirmar que não se deve julgar as mães que não planejaram o bebê, porque existe o desejo inconsciente das mulheres de serem mães. Observa-se, assim, uma tentativa de conceber a subjetividade do indivíduo sem contextualização, normatizando o desejo inconsciente de todas as mulheres em serem mães como se fosse a única explicação possível para a maternidade não planejada. Isso reforça ainda a perspectiva de que toda mulher deseja ser mãe e, no momento em que a gravidez acontece, generalizam-se as formas de se conceber a vida, enfatizando-se, até mesmo, a constituição familiar como prioridade na vida da mulher.

\section{Ełapa 3: a orlentação para a ação}

Neste nível de análise, a proposta é identificar as principais funções das construções discursivas. Observa-se que, embora os pais sejam apresentados como os principais responsáveis pelos cuidados do seu filho, é na mãe que se centra o cuidado no desenvolvimento do vínculo afetivo com o seu bebê: "Neste estado, chamado de preocupação materna primária, as mães - e também os pais - tornam-se capazes de se colocar no lugar do bebê. Isso significa que as mães desenvolvem uma capacidade incomum de se identificar com seus bebês". ${ }^{39}$ 
Entretanto, verificou-se, a partir de uma entrevista com a terapeuta ocupacional da UTI, que muitos bebês são abandonados, denunciando o descaso das mães para com seus próprios filhos:

\begin{abstract}
Nesse momento mesmo eu estou com 5 bebês de alta da UTI e as mães não vêm buscar [...] Uma tem história de droga, é usuária. A outra tem cinco filhos em casa e disse que não pode vir buscar agora. A outra, o bebê tem um problema neurológico e a mãe disse que não ia querer o bebê, já tem dois saudáveis em casa e não precisa desse. E a outra disse que vem, está ajeitando as coisas em casa mas vem buscar. E mais uma disse que tem mil problemas em casa e disse que não vem buscar. Ninguém pode julgar os problemas de cada uma.
\end{abstract}

Assim, verifica-se que a política do Programa propõe a forma correta e saudável de maternar baseada na ideia de família nuclear, mas desconsidera as diferenças socioeconômicas, geográficas e históricas de cada grupo social.

\title{
Etapa 4: o estudo dos posicionamentos
}

Neste item de análise, atenta-se às formas como os discursos presentes no documento oficial posicionam os atores que compõem o Programa Canguru. No Programa, as mães são posicionadas como agentes prioritárias para seu sucesso, sendo imprescindível contar com sua participação no desenvolvimento satisfatório do bebê. Enfatiza-se, por essa razão, a importância do vínculo afetivo a partir de uma concepção universal e generalizada do amor materno.

Os profissionais, por sua vez, são posicionados como transmissores/instrutores da forma saudável de maternar, que deve ser aceita e reproduzida entre as usuárias. "A adoção do Método Canguru visa fundamentalmente uma mudança de atitude no manuseio do recém-nascido de baixo peso com necessidade de hospitalização e da atitude de sua família". ${ }^{40}$

Desse modo, as mães e os outros familiares tornam-se apenas receptores dessas práticas e passam a ser cobrados pelo comportamento ideal de responsabilização pelo seu bebê.

\section{Etapa 5: o estudo das práticas}

Reserva-se este tópico para identificar e relacionar o tipo de práticas favorecidas pelas construções discursivas antes enumeradas. Isso requer uma exploração sistemática dos caminhos através dos quais essas construções e posicionamentos dos sujeitos nelas contidas abrem ou fecham oportunidades para a ação. 
${ }^{41}$ BRASIL, 2002, p. 46.

${ }^{42}$ BRASIL, 2002, p. 11.
Observa-se que o manual oferece alguns conceitos e passos a serem seguidos pela equipe técnica do Programa Canguru, de forma a acolher a mãe e a família no processo de favorecer o desenvolvimento do vínculo afetivo. Esses conceitos referem-se ao "acolhimento, comunicação, família ampliada, interação social e maternagem". ${ }^{41}$

Embora, em algum momento, o documento oficial atente para a necessidade de considerar o usuário a partir de sua história individual, desejos e sentimentos próprios, ao mesmo tempo a maioria dos textos posiciona pessoas e famílias como grupos homogêneos. Sustentando-se no modelo de família de classe média, negligencia as profundas diferenças socioculturais, especialmente entre estratos sociais diferenciados.

Evidencia-se também o caráter impositivo da política para as mães usuárias do SUS. Nos hospitais privados, esse método não é um programa de saúde, e sim uma opção, cabendo à mãe decidir pela participação ou não. Dessa forma, torna-se uma escolha para algumas mulheres e uma imposição para outras. A maioria das usuárias do SUS acaba por aceitar essa imposição, mas se fortalecem, ao mesmo tempo, a submissão e a falta de autonomia entre essas mulheres.

\section{Ełapa 6: as formas de subjetlvação possívels}

A relação entre os posicionamentos e as práticas dos atores sociais condiciona os processos de subjetivação, que podem determinar as formas de ser e estar no mundo, construindo realidades sociais e psicológicas.

O manual apresenta como objetivo "propor uma abordagem" 42 no intuito de construir nos profissionais a noção da importância do vínculo e do amor materno para o desenvolvimento saudável do recém-nascido prematuro. Tal finalidade é defendida como se os profissionais fossem capazes de incutir essas ideias na vida das mulheres participantes do Programa, apresentando-as como a única forma de maternar. Especificamente no caso do Programa Canguru, pelo fato de sua implantação e desenvolvimento virem determinados através de normas que regulam as formas de aplicação, estas tendem a ser acriticamente adotadas com um caráter autoritário.

Observou-se, através das conversas informais e entrevistas, que as mães passam a assumir uma postura passiva, reproduzindo o ideário da política em seus próprios discursos: "Funciona. Quando a gente fica mais tempo com ela [a filha] no canguru, ela aumenta rapidinho. Todo mundo fala isso aqui e na UTI" (mãe). Verifica-se também essa reprodução em relação à amamentação: "Porque o médico 
${ }^{43}$ Marshall KLAUS e John KENNELL, 1992; e KLAUS, KENNELL e Phyllis KLAUS, 2000

44 SPITZ, 1987

${ }^{45}$ BOWLBY, 1995. mesmo falou que quando a gente tá amamentando, o órgão [útero] da gente [...] logo fica bom. Por isso que eu acho que é bom pra gente" (mãe).

Entretanto, a observação participante denuncia o conflito presente nas usuárias ao desempenharem o papel que lhes é imposto. Mesmo apresentando a importância do Programa em seus discursos, muitas mães tinham crise de choro, isolamento e agressividade e/ou raramente colocavam o bebê na posição canguru, deixando-o na cama a maior parte do tempo.

\section{Discussão}

Em nenhum momento pretende-se questionar 0 potencial efeito positivo do Programa Canguru em relação ao desenvolvimento da ligação afetiva, à relevância do vínculo mãe-filho, ao ganho de peso e aos outros efeitos benéficos relacionados à saúde do bebê. Os estudos de Klaus e Kennell, ${ }^{43}$ nos EUA, foram os principais propulsores de mudanças nos cuidados hospitalares aos bebês prematuros e/ou de baixo peso. Desde a década de 1970, suas pesquisas com bebês internados em UTIs neonatais foram conclusivas para a afirmação de que, nesse ambiente, havia um maior distanciamento dos pais em relação ao filho. Essa situação acarretava um menor apego e pouco ou nenhum desenvolvimento do vínculo afetivo, o que iria desencadear histórias frequentes de maus-tratos e negligências com os bebês ao se integrarem ao ambiente familiar. Por outro lado, percebeu-se que um contato maior entre a mãe e o bebê favorecia a formação de vínculos.

Tais pesquisas reforçaram os trabalhos de René Spitz ${ }^{44}$ e de John Bowlby. ${ }^{45}$ Spitz estudou as consequências da privação socioafetiva, constatando que, após a separação de suas mães, as crianças hospitalizadas desenvolviam uma síndrome (depressão anaclítica) que, muitas vezes, culminava na morte de algumas delas. Bowlby também trabalhou a privação materna, baseando-se na qualidade dos cuidados parentais que uma criança recebe nos primeiros anos de vida, os quais são de importância vital para sua saúde mental futura. Essas ideias sobre as necessidades afetivas desde a tenra infância e o fato de se considerar $o$ comportamento materno como decorrente de sistemas inatos com uma base instintiva contribuíram para a construção e a manutenção do mito do amor materno.

No mesmo teor, os discursos do documento oficial valorizam a família nuclear idealizada típica da classe média, exaltando, através de conceitos psicanalíticos, a ideia do instinto materno. Esse discurso moralizador que se iniciou por volta do século XVIII continua, até hoje, cobrando 
${ }^{46}$ BADINTER, 1985.

das mulheres amor e cuidados incondicionais a seus filhos. Dessa forma, o papel social da mulher como pessoa passa a ser desconsiderado diante da idealização do papel materno.

Nesse sentido, Badinter ${ }^{46}$ aponta para a tendência em se confundir determinismo social e imperativo biológico. Apesar de se acreditar atualmente que o comportamento é uma construção social, na cultura ocidental a mulher é potencialmente considerada a partir de sua natureza biológica, em função da sua capacidade de gerar e parir filhos.

A aplicação do Programa Canguru tende-se a apoiar nessa perspectiva biologicista/psicoanalítica, trazendo à tona um conflito ético ao posicionar a mãe como mero instrumento para recuperação da saúde de seu filho. Atentando-se para essa observação, insiste-se na necessidade de uma reflexão acerca da forma como o Programa está sendo aplicado. Uma vez que seus princípios partem de uma concepção universal e generalizada do amor materno e da família, verifica-se uma tendência à reprodução dos discursos prescritivos nos serviços de atendimento. Dessa forma, desconsidera-se a subjetividade das pessoas envolvidas, assim como todos os condicionantes sociais, econômicos, culturais e familiares, os quais perpassam os posicionamentos em relação à experiência da maternidade e à vivência com um filho.

Assim, os discursos encontrados no documento oficial, carregados de juízos de valor e de posicionamentos idealizados acerca da maternidade, de um lado, normalizam o atendimento por parte dos funcionários do Programa e, de outro lado, anulam as possibilidades de as mães expressarem suas individualidades e a vontade em participarem ou não do Canguru.

Observa-se que, no cotidiano do atendimento, as práticas se voltam muito mais para a aplicabilidade técnica, faltando o diálogo com as mães e a consideração dos aspectos psicossociais do processo. Algumas mães se apresentam confusas ao serem solicitadas a falar do Programa e, quase sempre, associam os benefícios dessa prática exclusivamente para o seu bebê, esquecendo-se de que elas também fazem parte da intenção de fortalecer o vínculo afetivo.

Assim, nas entrevistas e nas conversas informais com as mães, o que se percebe é a reprodução do discurso dominante de que o Programa é benéfico apenas em função do aumento de peso do bebê. Sendo o aumento de peso uma exigência para a alta do bebê (em torno de 1.600 kg.), torna-se essa a principal preocupação das genitoras.

Entretanto, deve-se atentar para o fato de que, se a mãe não entende e não reflete sobre seu papel no Programa, em muitos casos, ela apenas 'empresta' seu corpo para a 
47 Roseni PINHEIRO e Madel Therezinha LUZ, 2003.

${ }^{48}$ Fernando ÁLVAREZ-URÍA e Julia VARELA, 1994. recuperação do seu bebê, o que a condiciona ao papel de incubadora humana.

Nota-se, ainda, que, ao deixar às custas da mãe e/ ou da família a responsabilidade de cuidar de uma criança prematura que está susceptível a desenvolver sequelas, o Estado isenta-se, em parte, da incumbência de promover sistemas de assistência adequados para as necessidades especiais de muitas dessas crianças. No caso concreto da maternidade em questão, observa-se, de fato, que não há nenhum tipo de seguimento terapêutico para essas crianças, uma vez recebida a alta do serviço.

\section{Algumas considerações finais}

As Normas de Atenção humanizada ao recémnascido prematuro e/ou de baixo peso - Método MãeCanguru discorrem sobre aspectos biológicos e psicológicos do comportamento materno, porém se abstêm de uma reflexão sobre os condicionantes sociais, culturais, econômicos e políticos que exercem influências nas experiências e nos processos de geração de sentidos nos cuidados dessas crianças.

Se as políticas de humanização visam justamente melhorar e qualificar o processo de interação entre os atores sociais, entende-se que tal mudança não pode ocorrer simplesmente através de normas, editais e cursos. Considerase que a reestruturação na forma de enxergar o outro deve caracterizar o movimento de humanização. É importante, para isso, considerar a complexidade e os processos de subjetivação desenvolvidos de acordo com as experiências pessoais e com as formas por meio das quais as pessoas significam o mundo à sua volta.

Ressalta-se que as políticas de saúde em geral, ao desconsiderarem a subjetividade dos seus usuários, formulando normas e discursos verticais que normalizam as práticas de intervenção, impõem à população assistida uma posição de submissão. ${ }^{47}$ Talvez, se o Programa, em lugar de uma postura autoritária, adotasse uma postura dialógica, refletindo com as mães sobre a importância desse tipo de cuidado, a participação dessas no Programa fosse mais eficaz. Contudo, para se libertar da perspectiva autoritária, não basta a boa vontade de profissionais e governantes, precisa-se pensar em alternativas de democratização do controle social que questionem a lógica sociopolítica tradicional predominante nesses espaços de saúde..$^{48}$

Além de informar e respeitar a vontade da pessoa em escolher determinado tratamento, articulando os avanços tecnológicos com o bom relacionamento, deve-se considerar também as condições de funcionamento dos serviços 
assistenciais. Considera-se importante oferecer tanto aos profissionais quanto aos usuários espaços de reflexão sobre seus respectivos papéis nos serviços de saúde. Apenas quando atores sociais em relação se convertem em uma coletividade torna-se possível a autotransformação, sendo essa coletividade atingida através desses espaços de reflexão.

\section{Referências bibliográficas}

ÁlVAREZ-URÍA, Fernando; VARELA, Julia. Las redes de la psicologia: análisis sociológico de los códigos médicopsicológicos. Spain: Libertarias; Prodhufi S.A., 1994.

ARÉSTEGUI, Raúl Urgino. "El Método Canguro em el Hospital Nacional Docente Madre Nino (HONADOMANI) 'San Bartolomé'". Paediatrica, v. 4, n. 3, p. 41-46, 2002.

ARIÈS, Phillip. História social da criança e da família. Rio de Janeiro: LTC, 1981.

BADINTER, Elisabeth. Um amor conquistado: o mito do amor materno. Rio de Janeiro: Nova Fronteira, 1985.

BERNARDES, Jefferson de Souza; MENEGON, Vera Sônia Mincoff. "Documentos de domínio público como produto e autores sociais". PSICO, Porto Alegre, v. 38, n. 1, p. 11-15, 2007.

BOWLBY, John. Cuidados maternos e saúde mental. São Paulo: Martins Fontes, 1995.

BRASIL. Secretaria de Políticas de Saúde. Área de Saúde da Criança. Atenção humanizada ao recém-nascido prematuro e/ou de baixo peso - Método Mãe-Canguru: manual do curso. Brasília: Ministério da Saúde, 2002. Disponível em: http://www.fiocruz.br/redeblh/media/ manualcanguru.pdf. Acesso em: 10 fev. 2010.

CARDOSO, Antonio Carlos et al. "Método Mãe-Canguru: aspectos atuais". Pediatria, São Paulo, v. 28, n. 2, p. 128134, 2006.

CARVALHO, Marcus Renato; PROCHNIK, Martha. Método MãeCanguru de atenção ao prematuro. Rio de Janeiro: BNDES, 2001. v. 1 (Coleção BNDS Social).

CHARPAK, Natalie. "Kangaroo Mother Care in Developing Countries". In: $5^{\text {th }}$ WORLD CONGRESS OF PERINATAL MEDICINE, 2001. p. 1023-1027.

DEVAULT, Marjorie; McCOY, Liza. "Institutional Ethnography, Using Interviews to Investigate Ruling Relations". In: GUBRIUM, Jaber; HOLTEINS, James (Eds.). Handbook of Interview Research. Thousand Oaks; London: Sage, 2002. p. 751-776.

DONZELOT, Jacques. A polícia das famílias. Rio de Janeiro: Edições Graal, 1986.

KLAUS, Marshall; KENNELL, John. Pais/bebê: a formação do apego. Porto Alegre: Artes Médicas, 1992. 
KLAUS, Marshall; KENNELL, John; KLAUS, Phyllis. Vínculo: construindo as bases para um apego seguro e para a independência. Porto Alegre: Artes Médicas, 2000.

LAMY, Zeni Carvalho et al. "Atenção humanizada ao recémnascido de baixo peso - Método Canguru: a proposta brasileira". Ciência \& Saúde Coletiva, v. 10, n. 3, p. 659668, 2005.

MINISTÉRIO DA SAÚDE. Portaria n 1.683. Norma de orientação para a implantação do Método Canguru. Diário Oficial da União, 12 jul. 2007.

MONTEIRO, Mario Francisco Giani; CERVINI, Ruben. Perfil estatístico de crianças e mães no Brasil: aspectos de saúde e nutrição de crianças no Brasil. Rio de Janeiro: Fundação Instituto Brasileiro de Geografia e Estatística (FIBGE), 1992.

MOURA, Solange Maria Sobottka Rolim; ARAÚJO, Maria de Fátima. "Produção de sentidos sobre a maternidade: uma experiência no Programa Canguru". Psicologia em Estudo, Maringá, v. 10, n. 1, p. 37-46, jan./abr. 2005.

PESQUISA NACIONAL POR AMOSTRA DE DOMICÍLIOS (PNAD). Ministério do Planejamento, Orçamento e Gestão. Instituto Brasileiro de Geografia e Estatística (IBGE), 2006.

PINHEIRO, Roseni; LUZ, Madel Therezinha. "Práticas eficazes $x$ modelos ideais: ação e pensamento na construção da integralidade". In: PINHEIRO, Roseni; CAMARGO JR, Kenneth Rochel (Orgs.). Construção da integralidade: cotidiano, saberes e práticas em saúde. Rio de Janeiro: UERJ; IMS; ABRASCO, 2003. p. 7-34. 228 p.

SALEM, Tânia. Sobre o "casal grávido": incursão em um universo ético. Tese (Doutorado) - PPGAS, Museu Nacional, Universidade Federal do Rio de Janeiro, Rio de Janeiro, 1987.

SILVA, Tânia Maria Gomes. "Família e historiografia". POLITEIA: His. e Soc., Vitória da Conquista, v. 2, n. 1, p. 37-46, 2002.

SMITH, Dorothy. Institutional Ethnography: A Sociology for People. Lanham: Altamira Press, 2005.

SPITZ, René Árpád. O primeiro ano de vida: um estudo psicanalítico do desenvolvimento normal e anômalo das relações objetais. São Paulo: Martins Fontes, 1987.

THERBORN, Göran. Sexo e poder: a família no mundo. São Paulo: Contexto, 2006.

TOMA, Tereza Setsuko. "Método Mãe Canguru: o papel dos serviços de saúde e das redes familiares no sucesso do Programa". Cadernos de Saúde Pública, v. 19, n. 2, p. 233-242, 2003.

TOMA, Tereza Setsuko; VENÂNCIO, Sónia Isoyama; ANDRETTO, Daniela de Almeida. "Percepção das mães sobre o cuidado do bebê de baixo peso antes e após implantação do Método Canguru em hospital público da cidade de 
São Paulo, Brasil". Rev. Bras. Saúde Matern. Infant., v. 7, n. 3, p. 297-307, 2007.

TRAVERSO-YÉPEZ, Martha Azucena. "Dilemas na promoção da saúde: reflexões em torno da Políica Nacional recentemente implementada". Interface-Comunic., Saúde, Educ., 2007. Disponível em: http://www.interface.org.br/arquivos/ aprovados/artigo8.pdf. Acesso em: 10 mar. 2010.

VILLAR, José et al. "Cesarian Delivery Rates and Pregnancy Outcomes: The 2005 WHO Global Survey on Maternal and Perinatal Health in Latin America". Lancet, v. 367, n. 9525, p. 1819-29, May 23, 2006.

WILLIG, Carla. Introducing Qualitative Research in Psychology. Adventures in Theory and Method. Buckingham: Open University Press, 2001.

WINNICOT, Donald. Os bebês e suas mães. São Paulo: Martins Fontes, 2001.

[Recebido em março de 2008 e aceito para publicação em maio de 2009]

\section{Motherhood in the Policy of Humanized Health Care for Premature and/or Underweight Babies - Kangaroo Program}

Abstract: The article aims to develop a reflection about the models of motherhood and family implicit in the official document edited by the Ministry of Health about the Kangaroo Program. It also explores the way the Program is developed at a Maternity Hospital in the North-Eastern part of the country, as it is presented as humanized health care for premature and/or underweight babies. The methodological perspective adopted is the foucauldian discourse analysis which focuses on the role of language in the configuration of the social and psychological life of the social actors involved. The analysis shows that there exists a comprehensive, prescriptive, and authoritarian discourse, positioning women as passive objects of intervention, through the idealization of a healthy motherhood and a typical nuclear middle class family.

Key Words: Prematurity; Kangaroo Program; Motherhood; Foucauldian Discourse Analysis. 